\title{
HIDROCEFALIA MULTILOCULADA
}

\author{
RELATO DE DOIS CASOS
}

MARILISA M. GUERREIRO*-NUBOR O. FACURE**- EDNEA A. SILVA***

RESUMO - Hidrocefalfa multiloculada é conceituada como quadro clínico-patológico que consiste de ventrículos aumentados e loculados e de cavidades porencefálicas paraventriculares. Apresentamos dois casos de hidrocefalia multiloculada, um provavelmente consequente a processo infeccioso do sistema nervoso central e outro em decorrência de malformaçăo congênita. Aspectos tomográficos compativeis ao diagnóstico são ressaltados. A etiopatogeria, o tratamento e o prognóstico são discutidos em face da literatura compulsada.

\section{Multiloculated hydrocephalus: report of two cases.}

SUMMARY - Multiloculated hydrocephalus is a clinicopathological entity consisting of enlarged, loculated ventricles and paraventricular poroencephalic cavities. We present two cases of multiloculated hydrocephalus: one due to infectious process of central nervous system and the other consequent to a congenital malformation. Tomographic aspects of this condition that permit the diagnosis are stressed. The pathophysiology, the management and the prognosis are discussed according to the available literature.

Hidrocefalia multiloculada tem sido pouco registrada 1,2 , provavelmente por ser raramente reconhecida como entidade isolada. Trata-se de quadro clínico-patológico que consiste de ventriculos aumentados e loculados e de cavidades porencefálicas paraventriculares 1,2,4-6,8,10,13,14. A apresentaçāo clinica é caracterizada por sinais de hidrocefalia, assim como crises epilépticas, retardo mental e sinais de deterioração ao exame neurológico. Essa condiçăo tem recebido diferentes designaçōes, tais como: septaçōes intraventriculares 5.14 , hidrocefalia multilocular 10 , doença cerebral policistica 4, compartimentalizaçāo ventricular 6 e membranas intraventriculares cerebrais 13.

Os autores apresentam dois casos de hidrocefalia multiloculada, um provavelmente consequente a processo infeccioso do sistema nervoso central (SNC) e outro em decorrência de malformação congènita do SNC. Sảo ressaltados os aspectos tomográficos compativeis ao diagnóstico e é discutida a conduta em face da literatura consultada.

\section{OBSERVAÇOEES}

Caso 1 - M.C.S., criança do sexo feminino, com 1 ano e 3 meses de idade, trazida a nosso Serviço por aumento excessivo do perimetro craniano. Nascida pré-termo, gestação sem intercorrências, parto normal, domiciliar, choro imediato e peso $=1600 \mathrm{~g}$. Ao nascimento notou-se presença de mielomeningocele em regiăo lombossacra, sendo levada a um hospital de sua região, em que foi submetida a correção cirúrgica com dois dias de vida. Nâo temos o relatório de sua internação. Segundo a māe, instalou-se uma derivaçāo ventriculo-peritoneal poucos dias após a primeira cirurgia. A criança permaneceu internada por 6 meses e recebeu alta sem válvula, que parece ter siđo retirada após complicaçós infecciosas. $\mathbf{A}$ internação em nosso Serviço apresentava perímetro cefálico de $49 \mathrm{~cm}$, fontanela bregmática ampla e normotensa, nāo sustentava a cabeça, não fixava o olhar, nāo mudava de posição e apresentava hemiparesia esquerda incompleta. A tomografia computadorizada craniana (TC) revelou presença de múltiplas cavidades contendo septos, tornando dificil a diferenciaçăo entre ventrículos e cistos paraventriculares (Fig. 1 A e B). Os lóculos diferem em tamanho, forma e numero. As membranas divergem em espessura, mas geralmente sâo mais proeminentes no local de aderência à parede. Há imagens semelhantes a espiculas que provavelmente representam sinais indiretos da presença de membranas finas. $O$ tecido nervoso residual não é uniformemente distribuido, sendo parcialmente preservado em algumas regiós es mais delgado em outras áreas. A criança foi submetida a derivação ventriculo-peritoneal em $\mathrm{Y}$,

Departamento de Neurologia da Faculdade de Ciências Médicas da UNICAMP: * Professora Assistente: ** Professor Adjunto; *** Médica Residente de Neuropediatria. 
dirigida às duas maiores cavidades. Houve estabilizacão do perímetro craniano. Novo exame tomográfico realizado 6 meses após a cirurgia não evidenciou qualquer alteração em relação ao anterior (Fig. $1 \mathrm{C}$ ). Nove meses após o evento cirúrgico seu exàme neurológico permanecia inalterado e a criança foi reinternada com diagnóstico de pneumonia, vindo a falecer por insuficiência respiratória. o exame anátomo-patológico mostrou inúmeras cavidades separadas por delgadas membranas (Fig. 2) que o exame microscópico revelou serem compostas por elementos fibrogliais.
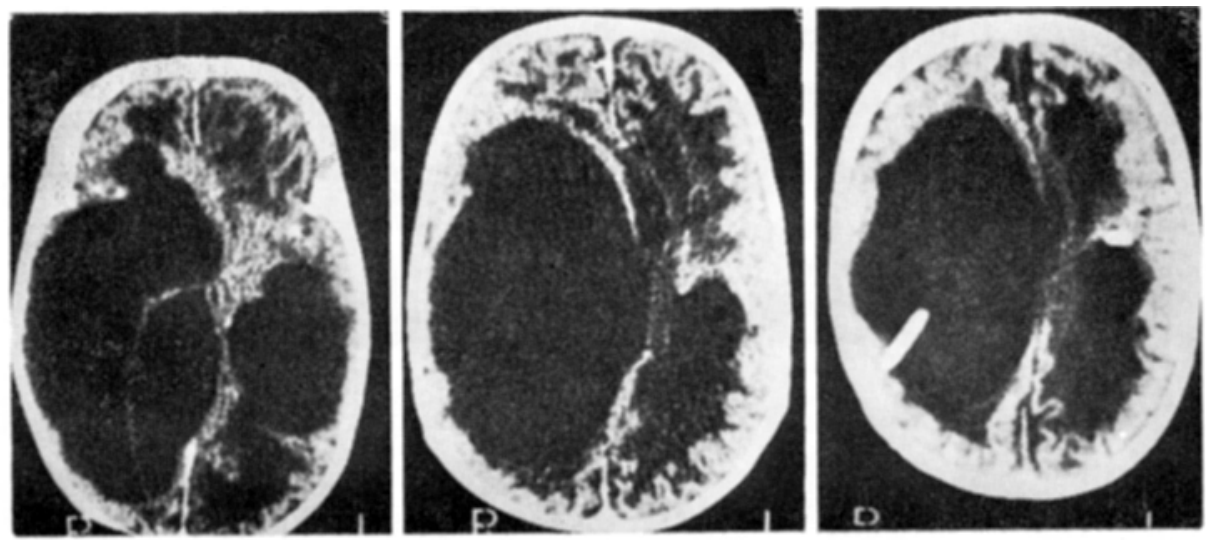

Fig. 1 - Caso 1. Tomografia computadorizada: a esquerda (A) e no meio (B), múltiplas cavidades contendo septos, os loculos diferem em tamanho, forma $\boldsymbol{e}$ numero, as membranas divergem em espessura mas geralmente são mais proeminentes no local da aderência à parede; à direita (C), após derivação ventrículo-peritoneal em $Y$, não evidenciando qualquer alteração em relação às anteriores.

Caso 2 - R.S., criança do sexo masculino, com 2 anos de idade, internada para correção de encefalocele parietal. Nascido a termo, após gravidez sem intercorrências, parto cesareano por indicaçăo materna, peso= $3700 \mathrm{~g}$. Houve cianose, não chorou e necessitou $O$. Primeíro filho de mãe jovem (17 anos). Foram notadas, ao nascimento, inúmeras malformações de SNC, face, pés e coração. Permaneceu internado em outro Serviço nos dois primeiros meses de vida para auxílio regpiratório e investigação, tendo sido submetido a duas derivaçós ventriculo-peritoneais, uma aos 6 meses e outra com 1 ano de idade. A investigação apresentava perímetro cefálico de $55 \mathrm{~cm}$, encefalocele parietal de aproximadamente $4 \mathrm{~cm}$ de diâmetro, retardo importante do desenvolvimento neuro-motor, cebocefalia, microftalmia esquerda, lábio leporino, fenda palatina ampla, pés com desvio interno, sindactilia parcial ou total de vários artelhos, movimentaçăo simétrica com reflexos presentes em todos os membros. A TC revelou presença de múltiplas cavidades de diferentes tamanhos (Fig. 3). Houve correçāo cirúrgica da encefalocele e durante sęu acompanhamento por 6 meses a criança não apresentou qualquer progresso neuropsicomotor.

\section{COMENTARIOS}

Hidrocefalia como sequela de meningite é evento bem conhecido 3,9. Entretanto, dilatação ventricular associada a múltiplos septos intraventriculares não tem sido registrada com frequência 1,2,4-6,14. Em lactentes, meningite frequentemente se associa a ventriculite $4,7,12$, ao contrário do que ocorre em crianças maiores ou adultos. A cicatrizaçăo de ependimite pode resultar em hidrocefalia, com formação de cistos intraventriculares multiloculados causados pelo desenvolvimento de sinéquias ependimárias 14. Outra complicação de meningite pode ser vasculite levando a infarte cerebral 8, o que justificaria a formação de cavidades paraventriculares. No caso 1 a criança chegou a nosso Serviço com 1 ano e 3 meses e, portanto, não temos seu estudo tomográfico anterior. Entretanto, pela história fornecida, aventamos a possibilidade de que a hidrocefalia multiloculada tenha se desenvolvido em decorrência de ventriculite secundária a meningite. No caso 2 a criança nos foi encaminhada com 2 anos e também não temos seu estudo tomográfico anterior. Entretanto, não há suspeita pela história de que o paciente tenha tido meningite ou ventriculite. Neste caso, aventamos a possibilidade de que as membranas intraventriculares sejam congênitas, como parte de amplo espectro de malformações apresentadas pela criança já 



Fig. 2 - Caso 1. Exame andtomo-patológico: inúmeras cavidades separadas por delgadas membranas.
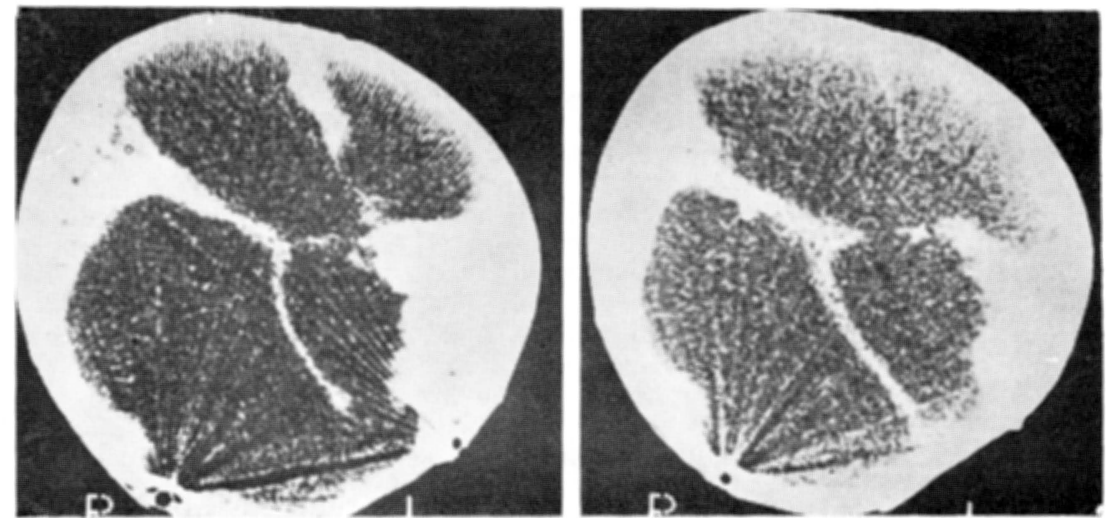

Fig. 3 - Caso 2. Tomografia computadorizada: presença de múltiplas cavidades contendo septos semelhantes aos do caso 1. 
ao nascimento. $\mathrm{Na}$ literatura compulsada encontramos registro de apenas um caso em que as septações foram consideradas de origem congênita 11. Nos demais relatos há referência a processos infecciosos anteriores 1-6,11-13.

As derivações são necessárias para controlar a hidrocefalia destes pacientes. A compartimentalização dos ventrículos laterais causada pelas septações pós-ventriculiticas interfere com a drenagem dos ventrículos, dificultando o procedimento cirúrgico. Portanto, inúmeras revisōes são necessárias ou então são adotadas derivaçōes bilaterais 1,5,12. Alguns autores propöem a abordagem direta dos cistos por craniotomia e subsequente remoção ou fenestração das membranas $1,8,11$. Desta forma, um sistema ventricular multiloculado pode ser transformado numa cavidade única facilitando a drenagem.

A dilatação progressiva dos cistos pode ser explicada por produção de líquido céfalo-raquidiano ou por formação de exsudato inflamatório dentro dos cistos 3 . As concentraçōes proteicas nas várias cavidades podem variar de maneira importante e este achado deve sugerir a presença de compartimentalização 5 . A importância da TC na detecção da hidrocefalia multiloculada foi ressaltada por vários autores $2,4,6,13,15$. Isto porque este exame não invasivo provou ser o procedimento diagnóstico mais importante na detecção da hidrocefalia multiloculada pois evidencia os septos direta e indiretamente. Septos mais espessos são facilmente identificáveis, enquanto septos mais finos podem ser suspeitados a partir de imagens semelhantes a espículas que se salientam das paredes das cavidades. Alguns autores sugerem que esta entidade deve ser melhor estudada por ventriculografia 5,16 , exame este não realizado em nossos pacientes.

A literatura é unânime em apontar um pobre prognóstico para esta condição 1,6,14. A maioria das crianças morre ou permanece severamente retardada. Os autores 1,10,13 que propöem a abordagem direta dos cistos aparentemente chegaram a resultados menos sombrios. Entretanto, o número de casos relatados é pequeno para definir a questão.

\section{REFERANCIAS}

1. Albanese V, Tomasello F, Sampaolo S - Multiloculated hydrocephalus in infants. Neurosurgery 8:641, 1981.

2. Albanese V, Tomasello F, Sampaolo S, Picozzi $P$ - Neuroradiological findings in multiloculated hydrocephalus. Acta Neurochir 60:297, 1982.

3. Berman PH, Banker BQ - Neonatal meningitis. Pediatrics 38:6, 1966.

4. Brown LW, Zimmerman RA, Bilaniuk LT - Polycystic brain disease complicating neonatal meningitis: documentation of evolution by computed tomography. J Pedlatrics 5:757, 1979.

5. Handler LC, Wright MGE - Postmeningitic hydrocephalus in infancy. Neuroradiology $16: 31,1978$.

6. Kalsbeck JE, DeSouza AL, KJeiman MB( Goodman JM, Franken EA - Compartmentalization of the cerebral ventricles as a sequela of neonatal meningitis. $J$ Neurosurg $52: 547,1980$.

7. Lee EL, Robinson MJ, Thong ML, Puthucheary SD, Ong TH, NG KK - Intraventricular chemotherapy in neonatal meningitis. J Pediatrics 91:991, 1977.

8. Leeds NE, Goldberg HI - Angiographic manifestations $n$ cerebral inflammatory disease. Radiology 98:595, 1971.

9. Lorber J, Pickering $D$ - Incidence and treatment of post-meningitic hydrocephalus in the newborn. Arch Dis Childh 41:44, 1966.

10. Rhoton AL, Gomez MR - Conversion of multilocular hydrocephalus to unilocular. J Neurosurg $36: 348,1972$.

11. Salmon JH - Isolated unilateral hydrocephalus following ventriculoatrial shunt. J Neur rosurg 32:219, 1970 .

12. Salmon JH $\rightarrow$ Ventriculitis complicating meningitis. Amer J Dis Child 124:35, 1972.

13. Savolaine ER, Gerber AM - Computerized tomography studies of congenital and acquired cerebral intraventricular membranes. J Neurosurg 54:388, 1981.

14. Schultz P, Leeds NE - Intraventricular septations complicating neonatal meningltis. J Neurosurg 38:620, 1973.

15. Snyder RD, Stovring J - The follow-up CT scan in childhood meningitis. Neuroradiology $16: 22,1978$.

16. Swick HM, Sty JR - Pediatric metrizamide ventriculography. Arch Neurol 37:582, 1980.

17. Taboada D, Olagüe R, Alonso A, Mulas F, Andrés V - Radiological diagnosis of periventricular and subcortical leukomalacia. Neuroradiology 20:33, 1980. 